\title{
OS ESFORÇOS DE MODERNIZAÇÃO DO ARSENAL NUCLEAR CHINÊS: BALANCEAMENTO INTERNO E TRANSFORMAÇÃO NO SISTEMA INTERNACIONAL CONTEMPORÂNEO
}

Layla Dawood ${ }^{1}$

Resumo: $O$ artigo visa a analisar os investimentos chineses em seu arsenal nuclear nos anos que sucederam ao fim da Guerra Fria. Argumenta-se que os esforços de modernização das armas nucleares chinesas estão inseridos no âmbito de um processo de "balanceamento interno" empreendido pela China em relação aos Estados Unidos da América (EUA). Para desenvolver esse argumento, a primeira seção deste artigo apresenta algumas considerações sobre o fenômeno do "balanceamento interno", esclarecendo seu embasamento conceitual-teórico. Em seguida, realiza-se uma breve revisão histórica do programa nuclear chinês durante a Guerra Fria. Finalmente, serão avaliados os esforços contemporâneos de modernização dos arsenais nucleares chineses à luz do modelo teórico que auxilia na verificação empírica do fenômeno do balanceamento interno.

Palavras-chave: China. Estados Unidos da América. Política Nuclear. Balanceamento Interno. Teoria da Balança de Poder. Armas Nucleares.

\section{THE EFFORTS TO MODERNIZE THE CHINESE NUCLEAR ARSENAL: INTERNAL BALANCING AND TRANSFORMATION IN THE CONTEMPORARY INTERNATIONAL SYSTEM}

Abstract: The article aims to analyze Chinese investments in its nuclear arsenal after the Cold War. It is argued that nuclear weapons modernization efforts are part of a process of "internal balancing" undertaken by China in relation to the United States of America. To develop this argument, the first section of this article discusses the phenomenon of "internal balancing", in order to clarify its conceptual and theoretical basis. Then, we carry out a brief historical review of the Chinese nuclear program during the Cold War. Finally, contemporary efforts to modernize Chinese nuclear arsenals are evaluated, in light of a theoretical model that allows the empirical verification of the phenomenon of internal balancing.

Keywords: China. United States of America. Nuclear Policy. Internal Balancing. Balance of Power Theory. Nuclear Weapons.

\section{LOS ESFUERZOS PARA MODERNIZAR EL ARSENAL NUCLEAR CHINO: BALANCEO INTERNO Y TRANSFORMACIÓN EN EL SISTEMA INTERNACIONAL CONTEMPORÁNEO}

Resumen: El artículo tiene como objetivo analizar las inversiones chinas en su arsenal nuclear en los años que siguieron al final de la Guerra Fría. Se argumenta que los esfuerzos por modernizar las armas nucleares chinas son parte de un proceso de "balanceo interno" emprendido por China en contra los Estados Unidos de América. Para desarrollar este argumento, la primera sección de este artículo presenta algunas consideraciones sobre el fenómeno del "balanceo interno", aclarando su base conceptual-teórica. A continuación, se realiza una breve revisión

\footnotetext{
${ }^{1}$ Universidade do Estado do Rio de Janeiro, Departamento de Relações Internacionais, Rio de Janeiro, Brasil, layladawood@hotmail.com, https://orcid.org/0000-0003-0708-1627.
} 
histórica del programa nuclear chino durante la Guerra Fría. Finalmente, los esfuerzos contemporáneos para modernizar los arsenales nucleares chinos serán evaluados a la luz del modelo teórico que apoya la verificación empírica del fenómeno del balanceo interno.

Palabras clave: China. Estados Unidos de América. Política Nuclear. Balanceo Interno. Teoría del Equilibrio de Poder. Armas Nucleares.

\section{Introdução}

Durante a década de 1990 e a primeira década dos anos 2000, inúmeros trabalhos na área de Relações Internacionais buscaram dar sentido à estrutura internacional que emergia com o fim da Guerra Fria, gerando uma série de análises sobre o sistema internacional inaugurado com a derrocada da União das Repúblicas Socialistas Soviéticas (URSS). À época, muitos teóricos Realistas concordavam que a estrutura emergente se caracterizava como unipolar, centrando-se no poderio dos Estados Unidos da América (EUA), mas havia divergências sobre a durabilidade dessa configuração sistêmica (LAYNE, 1993; WOHLFORTH, 1999; WOHLFORTH et al., 2007). Aqueles que caracterizavam a unipolaridade como um "momento" (um breve interlúdio entre a bipolaridade da Guerra Fria e outra configuração sistêmica) afirmavam que, rapidamente, voltariam a operar os mecanismos de balanceamento de poder, os quais fariam com que o sistema voltasse ao equilíbrio bipolar ou multipolar (LAYNE, 1993)².

Nesse contexto, um grupo de estudiosos Realistas buscou testar empírica e historicamente a chamada "teoria da balança de poder", segundo a qual o sistema internacional tende ao equilíbrio de poder e não à unipolaridade ou à hegemonia. Em linhas gerais, o equilíbrio de poder refere-se a uma condição estrutural caracterizada pela equivalência entre as capacidades tecnológicas, econômicas e, especialmente, militares das principais unidades políticas (potências) que compõem um dado sistema internacional. Esse equilíbrio pode se apresentar na forma da bipolaridade (quando existe certa equivalência entre as capacidades de dois pólos de poder) ou da multipolaridade (quando o equilíbrio se dá entre mais de dois pólos). Para alcançar o equilíbrio sistêmico, a teoria prevê que dois tipos de comportamento

\footnotetext{
2 Segundo o Realismo Estrutural nas Relações Internacionais, o sistema internacional é composto por: 1) uma estrutura material de poder e 2) unidades em interação. São consideradas unidades os principais arranjos organizacionais políticos de um dado momento histórico (na contemporaneidade, os Estados-nação figurariam como as principais unidades do sistema internacional). Isso não significa que inexistem outros atores internacionais, mas que os Estados possuem primazia por, potencialmente, definirem as regras do intercurso entre os vários atores internacionais. Por outro lado, a estrutura é definida, especialmente, pela distribuição de capacidades entre as principais unidades do sistema, as quais recebem o nome de pólos. Uma dada estrutura é caracterizada pelo número de pólos, podendo assumir os formatos unipolar, bipolar ou multipolar (WALTZ, 1979).
} 
estão à disposição dos Estados: o balanceamento interno (esforços internos de auto fortalecimento, notadamente, econômico, tecnológico e militar) e o balanceamento externo (formação de alianças militares entre potências como preparação para possíveis enfrentamentos bélicos) (WALTZ, 1979).

Os referidos testes teóricos concluíram que, em vários exemplos históricos, 0 balanceamento não deu causa ao fim de sistemas internacionais unipolares e que, portanto, esse comportamento não poderia ser caracterizado como um mecanismo de transformação sistêmica internacional. Wohlforth et al. (2007) defenderam que unipolos (ou hegêmonas) decaem por fenômenos relacionados à super extensão imperial (gastos demasiados com defesa e consequente perda de dinamismo econômico) e/ou pela intervenção de atores externos aos sistemas (no caso de sistemas históricos anteriores ao atual sistema globalizado).

A obra de Wohlforth et al. (2007) é bastante convincente no que se refere ao balanceamento externo, a saber: historicamente, a formação de alianças militares contrárias ao unipolo não se mostrou capaz de produzir a queda hegemônica e a consequente mudança de sistemas unipolares. No entanto, a inefetividade do balanceamento interno na produção da mudança estrutural internacional não foi comprovada empiricamente pelos trabalhos que objetivaram testar a teoria da balança de poder.

O debate sobre o apoio empírico da teoria da balança de poder adquire especial relevância no contexto da análise sobre a atual superação (ou não) do sistema unipolar inaugurado com o fim da Guerra Fria. Para o Realismo Estrutural, um sistema unipolar seria um sistema desequilibrado, dada a concentração de poder em uma única super potência ou pólo. Assim, para a teoria da balança de poder, uma das formas de avaliar a ocorrência de um processo de mudança estrutural de um sistema unipolar seria pela via da identificação empírica dos mecanismos de produção do equilíbrio sistêmico. Em especial, é preciso verificar a ocorrência do balanceamento realizado por candidatos a pólo contra o poderio dos EUA.

Nesse sentido, este artigo pretende colaborar para o referido debate, analisando a posição relativa da República Popular da China no sistema internacional contemporâneo. Para tanto, analisar-se-á o estado atual das capacidades nucleares desse país em relação ao poderio nuclear dos EUA. É importante destacar que, contrariando os críticos da teoria da balança de poder, partimos do pressuposto de que tal teoria contém em si mesma uma explicação de cunho Realista para a mudança estrutural. Isso porque o balanceamento interno, 
quando bem-sucedido, resulta na ascensão de novos pólos, potencialmente transformando sistemas unipolares em bipolares e sistemas bipolares em multipolares. Em outras palavras, uma teoria Realista da mudança estrutural internacional estaria conectada ao fenômeno do balanceamento interno.

Diante da inegável importância das capacidades nucleares na caracterização dos pólos sistêmicos na contemporaneidade, objetiva-se investigar o aprimoramento das armas nucleares chinesas como parte de um processo de balanceamento interno empreendido pela China em relação aos EUA. Para tanto, a primeira seção deste artigo apresenta um modelo teórico para a caracterização e a identificação empírica do fenômeno do balanceamento interno. Em seguida, será realizada uma retrospectiva histórica do programa nuclear da China. Finalmente, o artigo analisa os recentes esforços chineses de modernização nuclear, contrastando-os ao modelo teórico de balanceamento interno aqui proposto.

\section{O balanceamento interno como mecanismo de mudança internacional}

O balanceamento interno é definido por um conjunto de ações estatais que possuem o potencial de reduzir o gap entre as capacidades de poder do(s) pólo(s) ascendente(s) e do(s) pólo(s) estabelecido(s), aumentando as chances de sucesso dos primeiros em relação aos segundos na eventualidade da ocorrência de uma grande guerra sistêmica (isto é, de uma guerra entre as principais potências de um dado sistema internacional) (DAWOOD, 2013). O quadro abaixo resume as atividades que caracterizam o processo de balanceamento interno:

\section{Quadro 01: Balanceamento Interno}

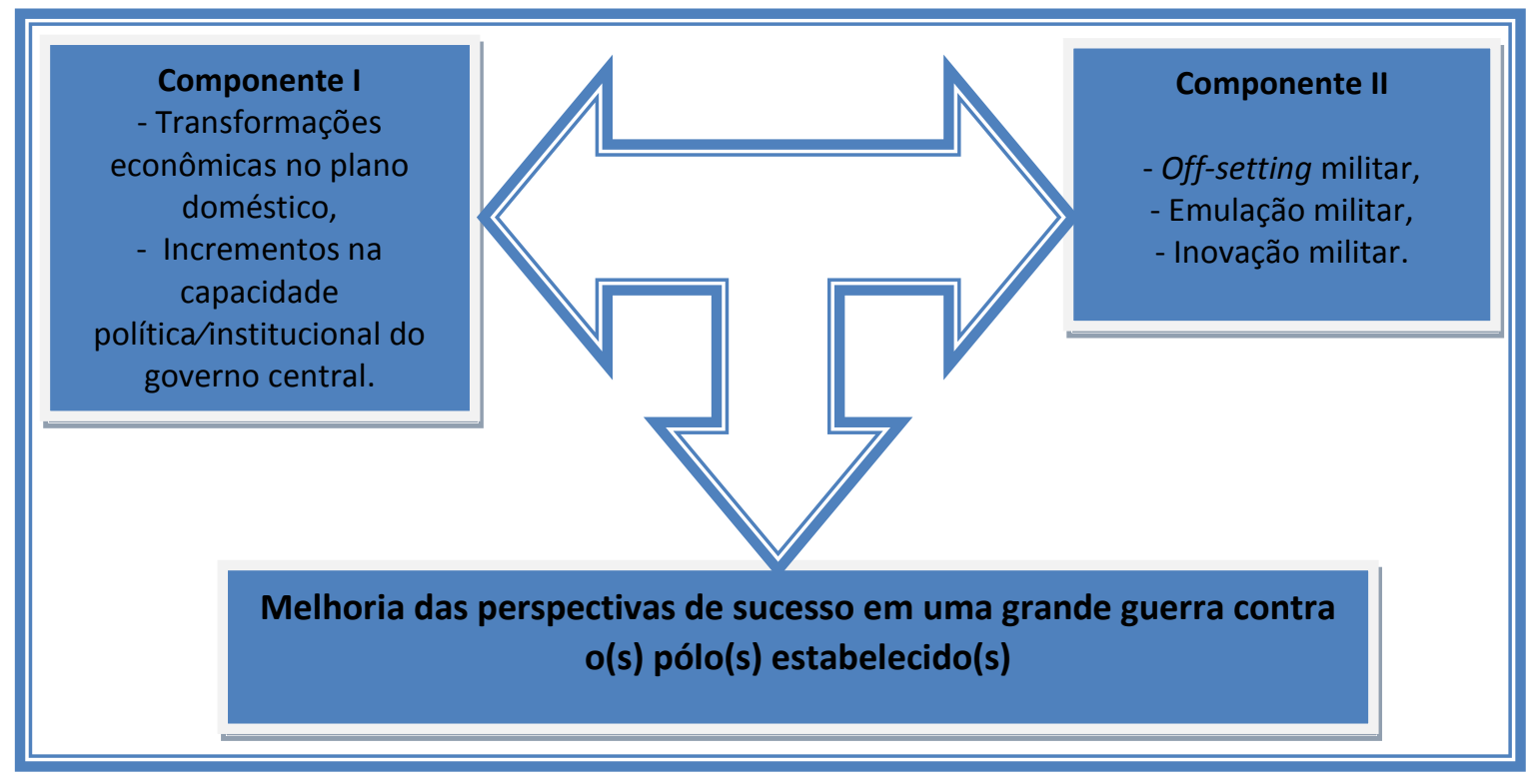

Fonte: Representação realizada com base no modelo teórico produzido por Dawood (2013). 
Conforme ilustrado acima, o "balanceamento interno" compreende uma dimensão doméstica de caráter político e econômico (a qual estabelece as bases que possibilitam o início do balanceamento interno e que permitem a manutenção desses esforços no tempo) e uma dimensão militar (que envolve comportamentos reativos às capacidades bélicas do Estado dominante). Essa última pode tomar a forma de pelo menos três tipos de comportamentos: off-setting, emulação e/ou inovação. Em linhas gerais, o off-setting compreende a aquisição de capacidades que não se assemelham às capacidades de um potencial adversário, mas que permitem lidar com tais capacidades na eventualidade de um confronto direto (Ex.: aquisição de submarinos para o enfrentamento dos porta-aviões de um adversário). Já a emulação envolve a tentativa de aquisição e/ou desenvolvimento de capacidades similares àquelas que, em princípio, conferem superioridade ao adversário (Ex.: tentativa de aquisição ou de desenvolvimento próprio de um portaaviões). Finalmente, a inovação significa a superação do estado da arte bélico de um dado momento histórico, que pode resultar, no limite, na superação das capacidades militares do adversário.

Desse modo, para analisar empiricamente a ocorrência da componente militar do balanceamento interno, é necessário identificar quais são as capacidades bélicas que constituem os fundamentos da proeminência do(s) Estado(s) dominante(s) em um dado sistema. Nesse sentido, este artigo baseia-se no pressuposto de que dois conjuntos principais (embora não excludentes) de capacidades militares constituíram as bases do poder militar dos EUA desde o fim da Guerra Fria: seu arsenal nuclear e suas forças navais. Isso se deve ao fato de que essas são as principais capacidades bélicas que possibilitam a projeção do poder militar dos EUA para outras regiões que não as Américas e, em especial, para a Ásia.

Se o arsenal nuclear estadunidense é um dos fundamentos de sua proeminência, espera-se que um candidato a pólo reaja a essas capacidades na busca de uma distribuição internacional de poder mais favorável ${ }^{3}$. Em outras

\footnotetext{
${ }^{3}$ Note-se que, ao estudar a distribuição de capacidades nucleares entre EUA e China, este artigo não necessariamente defende que uma guerra nuclear seja provável entre esses países. Tampouco se argumenta que uma guerra convencional seja inevitável entre a China e os EUA. Em realidade, defende-se que, para qualificar como um pólo sistêmico, dentre outras capacidades de poder, a China precisa estar preparada para resistir a possíveis chantagens empreendidas pelos EUA por meio da ameaça de uso da força e, particularmente, de armas nucleares. A incapacidade de reação a uma chantagem desse tipo tornaria a China extremamente vulnerável aos EUA, não podendo, nesta eventual situação, ser qualificada como um pólo sistêmico. No entanto, reconhecemos que a tendência é que tanto o uso efetivo de armas nucleares, quanto a ameaça de uso sejam realizadas apenas em situações limite, em que estejam em jogo interesses considerados vitais, figurando como último recurso na deliberação. Em outras palavras, o uso ou ameaça de uso de armas nucleares por
} 
palavras, para verificar empiricamente a ocorrência do balanceamento interno, este artigo busca observar o comportamento da China em relação às armas nucleares. Especificamente, busca-se identificar a presença dos comportamentos de off-setting, emulação e/ou inovação dos chineses em relação ao arsenal nuclear estadunidense. Além disso, o artigo avalia os resultados efetivos dos esforços de modernização nuclear da China. Essa avaliação ocorre porque, de acordo com o modelo teórico aqui utilizado ${ }^{4}$, para ser considerado como parte de um processo de balanceamento interno, um grupo de ações precisa resultar no aumento das chances de sucesso por parte da potência ascendente em uma guerra sistêmica contra o(s) pólo(s) adversário(s) dominante(s).

\section{O programa nuclear chinês durante a Guerra Fria}

Durante a década de 1950, a política nuclear declaratória dos EUA estabelecia que, no caso de hostilidades envolvendo seus principais adversários, o uso efetivo de armas nucleares seria considerado. Ameaças de ataque nuclear contra a China chegaram a ocorrer durante a Guerra da Coreia e a crise do Estreito de Taiwan (1954-1955). Assim, o início do programa nuclear chinês está fortemente ligado ao objetivo de evitar novas chantagens nucleares empreendidas por potências estrangeiras contra esse país (LEWIS; LITAI, 1988).

Diante da aliança entre a China e a URSS nos anos 1950, o programa nuclear soviético serviria de base inicial para o programa nuclear chinês, cujo desenvolvimento foi caracterizado por uma fase inicial de dependência da tecnologia soviética, até chegar a uma fase final de autossuficiência, quando o auxílio soviético foi interrompido. A fase de dependência nuclear ocorreu de 1955 a 1958, resultando em ganhos em treinamento, recursos, projetos e equipamentos para a China. Entre 1959 e 1960, teve lugar uma fase mista, quando a China adotou uma abordagem de via dupla para as armas nucleares: de um lado, buscava a assistência dos soviéticos, mas, de outro, investia na futura autossuficiência. Os anos de independência começaram após a saída dos especialistas soviéticos da China no início dos anos 1960. As diferentes visões de Mao Tsé-tung e Nikita Khrushchov

grandes potências não é necessariamente provável, mas, sim, possível. Diante dessa possibilidade, defendemos que pólos em ascensão só podem ser assim classificados se possuírem os meios de força necessários para reagir aos meios de força das potências estabelecidas.

4 Para maiores informações sobre o modelo teórico que busca caracterizar o fenômeno de balanceamento interno e apresentar ferramentas para a sua verificação empírica, vide: DAWOOD, Layla Ibrahim Abdallah. China versus the United States: is bipolarity back? A study of Internal Balancing as a possible source of international systemic change. Tese (Doutorado em Relações Internacionais)-Pontifícia Universidade Católica do Rio de Janeiro, Rio de Janeiro, 2013. 
sobre as implicações estratégicas das armas nucleares estavam entre as causas da cisão sino-soviética (LEWIS; LITAI, 1988).

Entre 1962 e 1964, os técnicos chineses superaram dois problemas principais: o domínio da tecnologia de enriquecimento de urânio e o desenvolvimento de um iniciador de nêutrons. Para enfrentar esses desafios, os chineses seguiram um caminho de emulação e inovação. Usufruindo da chamada "vantagem do atraso", os cientistas chineses tomaram conhecimento das experiências de outros países, evitando erros dispendiosos. Cada movimento era aprovado pelas autoridades chinesas após análise das iniciativas adotadas por outras nações, com atenção especial ao programa nuclear estadunidense. Isso foi possível porque muitas descobertas científicas estadunidenses estavam disponíveis abertamente em publicações internacionais especializadas (LEWIS; LITAI, 1988, p. 107).

Liu Xiyao (vice-ministro da Defesa Nacional) reconheceu que: "Sem a ajuda soviética (...) seria impossível conseguirmos tão rápido sucesso na fabricação de bombas atômicas e de hidrogênio". Além disso, Liu afirma que a China não usufruía de "nenhum dado científico ou técnico secreto sobre o desenvolvimento do hidrogênio", mas que os relatórios internacionais de amplo acesso "contribuíram para a unificação de nossas ideias e a determinação de nossos objetivos" (apud LEWIS; LITAI, 1988, p. 199, tradução nossa).

Quanto aos sistemas de entrega das armas nucleares, Lewis e Hua (1992) destacam que a assistência soviética direta foi escassa. Após a decisão de desenvolver mísseis balísticos em meados da década de 1950, os chineses procuraram a ajuda dos soviéticos, que forneceram dois tipos de mísseis: o R-1 e o R-2. No entanto, o alcance e a carga desses mísseis eram muito limitados. Isso levou os chineses a iniciarem, no final dos anos 1950, o desenvolvimento de uma série de mísseis conhecida como Dongfeng ou míssil balístico DF. O primeiro DF foi inspirado no míssil soviético R-12. Apesar do fato de a URSS se recusar a fornecer esse míssil à China, estudantes chineses na URSS obtiveram informações importantes por meio de entrevistas diretas com os profissionais envolvidos no desenvolvimento e produção do R-12 soviético (LEWIS; HUA, 1992, p. 13).

Em relação às preocupações estratégicas que guiaram o processo de produção de mísseis, a tendência inicial era claramente a de reagir ao arsenal nuclear dos EUA. Nos anos 1960, os chineses lançaram um plano de construção de quatro tipos de mísseis em oito anos. Cada tipo de míssil teria um alcance diferente 
com base em um alvo imaginário específico. Os alvos imaginários no plano original de 1964 eram os EUA e seus aliados: Japão (DF-2), Filipinas (DF-3), Guam (DF-4) e EUA continentais (DF-5). Em 1969, com a intensificação das tensões sinosoviéticas, os soviéticos foram incluídos como possível alvo do DF-4 (LEWIS; LITAI, 1988, p. 212; LEWIS; HUA, 1992).

Mesmo com o fim da assistência direta da URSS à China, a influência soviética persistiu no sentido de que os cientistas chineses seguiram a maneira soviética de construir mísseis balísticos com propulsores líquidos (LEWIS; HUA, 1992, p. 21). Por outro lado, para armazenar seu primeiro míssil balístico intercontinental (DF-5), os chineses estudaram cuidadosamente os meios estadunidenses de armazenamento, optando por manter seus mísseis em silos tal qual os EUA armazenavam o Titan II (míssil similar ao DF-5 no arsenal dos EUA) (LEWIS; HUA, 1992, p. 24).

Finalmente, a decisão de construir um submarino nuclear lançador de mísseis balísticos (Ship Submersible Ballistic Missile Nuclear Powered - SSBN, sigla em inglês) foi tomada no final dos anos 1950. Ao contrário do que foi feito pelos EUA e pela URSS, as autoridades da China decidiram desenvolver, concomitantemente, 0 submarino e o míssil balístico que seria nele utilizado (Submarine-launched Ballistic Missile - SLBM, sigla em inglês), lançando ao mesmo tempo o "Projeto 09" (o programa de desenvolvimento do submarino) e o "Projeto JL" (o programa de desenvolvimento de mísseis) (LEWIS; LITAI, 1994, p. 5).

No início desses projetos, os chineses procuraram assistência soviética, mas a inauguração dos programas coincidiu com a deterioração da aliança sino-soviética. Ao se recusar a ajudar os chineses na construção de um submarino nuclear próprio, Nikita Khrushchov teria afirmado: "Não considero que vocês consigam desenvolver tecnologias tão complicadas quanto as necessárias para um submarino nuclear. Vocês não precisam gastar muito dinheiro. Uma vez que a União Soviética tenha submarinos nucleares, vocês já os terão. Podemos criar uma flotilha conjunta" (apud LEWIS; LITAI, 1994, p. 18, tradução nossa). Diante disso, acredita-se que Mao Tsétung respondeu: "Teremos que construir submarinos nucleares, mesmo que demore 10.000 anos!" (apud LEWIS; LITAI, 1994, p. 18, tradução nossa).

Apesar de não ter sido fornecida ajuda soviética formal ao programa do submarino nuclear chinês, é possível dizer que os chineses se basearam na tecnologia soviética para construir seu primeiro submarino nuclear. Isso ocorreu porque, pelos termos do último acordo de assistência naval entre a URSS e a China, 
assinado no final de 1958, Moscou licenciou a construção chinesa de um submarino convencional armado com mísseis balísticos, um submarino de ataque, navios torpedo, um míssil submarino-à-superfície e um míssil navio-a-navio. Este acordo ajudou os chineses na aquisição de tecnologia de propulsão e orientação de mísseis, bem como na construção de submarinos (LEWIS; LITAI, 1994, p. 17).

Por outro lado, apesar de terem que buscar soluções próprias na construção de um SSBN (submarino nuclear lançador de mísseis balísticos) e um SLBM (míssil balístico lançado de submarino), também nesse caso os chineses tiveram acesso a publicações internacionais abertas que relatavam o desenvolvimento dessas capacidades nos EUA. Os programas estadunidenses para a construção de SSBNs e SLBMs foram acompanhados de perto pelas autoridades e técnicos da China. Ao narrar a história do design do SSBN chinês, Lewis e Litai (1994) se referem muitas vezes à "leitura atenta do crescente número de publicações sobre o programa Polaris $5^{5 \prime}($ p. 53)

Diante dessa rápida retrospectiva histórica, é possível dizer que, durante a Guerra Fria, comportamentos chineses condizentes com o balanceamento interno (sob a forma de off-setting, emulação e inovação) ocorreram tanto em relação ao programa nuclear soviético quanto ao estadunidense. As declarações das autoridades chinesas para justificar a aquisição de armas nucleares enfatizaram o objetivo de conter o "imperialismo estadunidense" e evitar a "chantagem nuclear" eventualmente perpetrada pelos EUA. Além disso, como mencionado acima, os planos iniciais de construção de mísseis tinham o território dos EUA e seus aliados como alvos em potencial. Consequentemente, desde o início, a aquisição chinesa de armas nucleares poderia ser explicada como uma tentativa de compensar as capacidades nucleares estadunidenses, configurando, portanto, o comportamento de off-setting.

$O$ modelo inicialmente emulado pelos chineses para lidar com as armas nucleares dos EUA foi o soviético. No entanto, o programa nuclear chinês não pode ser descrito simplesmente como resultado de emulação da URSS. Após a ruptura com os soviéticos e diante da bipolaridade sistêmica, a China teve que responder aos arsenais de EUA e URSS. Para tanto, os chineses emulariam as capacidades nucleares de ambas as superpotências. A China também inovou para atingir o

\footnotetext{
5 O Polaris foi o primeiro míssil balístico estadunidense lançado de submarinos. Para maiores informações, ver: https://www.britannica.com/technology/Polaris-missile.

${ }^{6}$ Para chegar a essa conclusão, Lewis e Litai (1994) afirmam ter recorrido a memoriais e artigos técnicos escritos por especialistas envolvidos no projeto chinês.
} 
objetivo de construir seu próprio arsenal nuclear. Em especial, sabe-se que inovações técnicas ocorreram no que diz respeito ao projeto da primeira ogiva nuclear (ver LEWIS; LITAI, 1988, p. 167).

Contudo, apesar do programa nuclear chinês poder ser descrito como uma conquista considerável, no sentido de que a China testou com sucesso seu primeiro dispositivo nuclear em 1964 e seu primeiro míssil balístico intercontinental em 1971 (LEWIS; HUA, 1992), não se pode ignorar que o arsenal construído por este país durante a Guerra Fria tinha proporções bastante modestas quando comparado às demais potências nucleares.

Especialistas estimam que, em 1984, a China possuía apenas dois mísseis que poderiam atingir o território continental dos EUA (o DF-5) e sete do mesmo tipo em 1994 (JEFFREY, 2007, p. 69). Consequentemente, é importante investigar até que ponto os esforços chineses foram suficientes para melhorar sua posição no sistema internacional durante a Guerra Fria.

Note-se que a investigação sobre os resultados do programa nuclear chinês para a melhoria da posição deste país no sistema internacional está relacionada a uma questão técnica/estratégica, qual seja: a quantidade e a qualidade de poder nuclear necessário para alcançar o sucesso da estratégia de dissuasão ${ }^{7}$. Embora as características específicas do comportamento chinês durante a Guerra Fria possam ser contestadas, há consenso entre os estudiosos ocidentais em denominá-lo como dissuasão (mais conhecida, em inglês, como deterrence). E os próprios chineses também tendem a concordar com essa caracterização, que é apoiada pelas palavras de Deng Xiaoping em uma reunião realizada em 1983:

\footnotetext{
Enquanto vocês tiverem alguma força de dissuasão, nós também teremos alguma; mas não queremos muito. Será suficiente apenas possuir armas nucleares. Coisas como armas estratégicas e forças de dissuasão existem para assustar os outros. Elas não devem ser usadas em um primeiro ataque. Mas nossa posse terá algum efeito. A posse limitada de armas nucleares exerce alguma pressão. Continua sendo nossa posição a de que iremos desenvolver um pouco [de armas nucleares]. Mas o desenvolvimento será limitado. Dissemos repetidamente que nossa pequena quantidade [de armas nucleares] não é nada. É apenas para mostrar que também temos o que vocês têm. Se vocês quiserem nos destruir, vocês precisam sofrer alguma punição (apud YUNZHU, 2005, p. 3 , tradução nossa).
}

\footnotetext{
${ }^{7}$ A estratégia da dissuasão nuclear consiste na ameaça de retaliação nuclear em resposta a um primeiro ataque nuclear empreendido por um ator adversário. Dentre outros fatores, o funcionamento da estratégia depende da credibilidade da ameaça (especialmente relacionada à posse de capacidade retaliatória efetiva e operacional).
} 
Nesse sentido, pode-se dizer que a dissuasão nuclear funcionou para a China não em função do tamanho de seu arsenal, mas apesar dele. Para Goldstein (2000), os chineses confiaram no entendimento de que a revolução nuclear resultaria em um novo ambiente estratégico internacional, no qual a China poderia garantir uma capacidade dissuasória mínima, particularmente se aproveitando da incerteza de seus adversários sobre a extensão das forças retaliatórias que teria à sua disposição, bem como das circunstâncias em que as armas nucleares poderiam ser empregadas pela China. O sucesso da dissuasão chinesa estaria, portanto, apoiado em uma estratégia de manipulação da racionalidade: a falta de confiança de que a China se comportaria racionalmente derivava, em especial, da possibilidade de lançamento acidental de armas nucleares (dado o desenvolvimento incipiente de estruturas de comando e controle nesse país) (p. 131-133).

A despeito do funcionamento da dissuasão, argumenta-se aqui que a aquisição de armas nucleares teve o efeito de melhorar apenas em alguma medida a posição internacional chinesa durante a Guerra Fria, mas que não foi suficiente para transformar a China em um pólo sistêmico ${ }^{8}$. Em outras palavras, o balanceamento interno chinês foi apenas parcialmente bem-sucedido durante a Guerra Fria. Essa conclusão é apoiada pela seguinte análise contrafactual: na hipótese de que as tensões tivessem se acirrado entre os EUA e a China, culminando em um conflito envolvendo armas nucleares, o arsenal chinês seria vulnerável a um primeiro ataque (ou mesmo à ameaça de um primeiro ataque) por não possuir a chamada capacidade de retaliação ou de segundo ataque (em inglês, second strike capabilities). Caso os EUA realizassem um primeiro ataque nuclear à China, esse poderia ser devastador e anular a capacidade chinesa de retaliação nuclear. Note-se que a capacidade retaliatória nuclear foi uma das bases do poderio bélico das duas principais superpotências durante a Guerra Fria.

A implantação do Trident II-D5 nos EUA colocou em dúvida o já frágil arsenal nuclear chinês, uma vez que tal míssil era preciso o suficiente para ameaçar os silos nucleares chineses. Por outro lado, se envolvida em uma guerra nuclear contra a URSS durante a Guerra Fria, a situação da China seria ainda pior, tendo em vista a proximidade geográfica entre os países, que promoveria rapidez no tempo de chegada dos mísseis soviéticos ao território chinês e reduziria o tempo de resposta do país atacado. Adicionalmente, acredita-se que os soviéticos tinham informações

${ }^{8}$ Certamente, do ponto de vista econômico e tecnológico, a China tampouco alcançou a posição de pólo durante a Guerra Fria. Não obstante, o foco deste artigo é a análise dos esforços de modernização militar e seus resultados. 
sobre a localização exata das armas nucleares chinesas, o que facilitaria um primeiro ataque contra os arsenais nucleares chineses, potencialmente desarmando o país de sua capacidade retaliatória (JEFFREY, 2007).

Em suma, embora a China tenha empreendido off-setting, emulação e inovação nuclear durante a Guerra Fria, aumentando seu potencial de exercício da estratégia de dissuasão contra os EUA e a URSS, tais ações não se encaixam inteiramente na caracterização do fenômeno de balanceamento interno aqui proposto, uma vez que contribuíam pouco para incrementar as chances de sucesso da China em uma eventual guerra nuclear contra os EUA ou a URSS.

\section{O arsenal nuclear chinês após o fim da Guerra Fria}

O objetivo desta seção é verificar se a China está balanceando internamente o poder nuclear dos EUA e se esse comportamento tem contribuído para melhorar a posição da China no sistema internacional contemporâneo. Para esse fim, mais uma vez, verificar-se-á a presença dos comportamentos que caracterizam o balanceamento interno (off-setting, emulação ou inovação) e se as ações chinesas reduzem a lacuna entre as capacidades nucleares dos EUA e da China.

Em resposta a essas perguntas, argumentamos que os comportamentos de off-setting, emulação e inovação estão acontecendo, como ocorreram durante a Guerra Fria. No entanto, atualmente, os resultados dessas ações parecem estar mais próximos da definição de balanceamento interno defendida neste artigo, uma vez que aumentam a capacidade de sobrevivência das armas nucleares chinesas a um possível primeiro ataque nuclear, criando capacidades mais robustas de realização de um ataque retaliatório pela China (em inglês, second strike capabilities).

Mudanças organizacionais foram recentemente promovidas nas forças armadas chinesas. A partir de dezembro de 2015, a antiga Segunda Força de Artilharia (fundada em 1966) tornou-se um braço autônomo das forças armadas da China, recebendo o nome de Força dos Mísseis (em inglês, People's Liberation Army Rocket Force, ou PLARF). Tal qual sua antecessora, essa nova força responsabiliza-se pelos mísseis convencionais e nucleares lançados por terra, sendo descrita por Xi Jinping como central para a dissuasão estratégica chinesa e para a garantia do status de grande potência a esse país. Ainda de acordo com o presidente chinês, tal força deve possuir capacidades nucleares e convencionais, 
estando preparada para conduzir "uma dissuasão abrangente" e operações de warfighting (GATES; NI, 2019, p. 3).

Para Gates e Ni (2019), "embora a demanda pela posse de capacidades nucleares e convencionais não seja nova, a ênfase na dissuasão abrangente e no warfighting é significativa" (GATES; NI, 2019, p. 3, tradução nossa). Esses autores destacam ainda a exortação de Xi para que a nova força incremente sua habilidade de exercício do "balanceamento estratégico" (战略制衡):

\begin{abstract}
A despeito do fato de que o termo não foi definido explicitamente, fontes das forças armadas chinesas frequentemente advogam em favor do uso de capacidades assimétricas como meios de balanceamento, defesa e dissuasão de adversários mais fortes. Mesmo que Xi não tenha especificado os alvos desse 'balanceamento estratégico', não há dúvidas de que esse comportamento está direcionado ao maior competidor estratégico da China, os EUA, e, em menor extensão, à Rússia e à Índia. Esse termo sinaliza a atribuição de maior expectativa sobre a nova força e na sua capacidade de contribuir para a posição estratégica da China (GATES; NI, 2019, p. 4, tradução nossa).
\end{abstract}

O uso dos termos "warfighting" e "balanceamento" pelas autoridades chinesas alimenta a teoria de que a China estaria mudando sua política nuclear. No entanto, pronunciamentos oficiais chineses sobre armas nucleares reiteram que a política nuclear declaratória da China não sofreu alterações desde o fim da Guerra Fria:

A China sempre perseguiu uma política de não primeiro uso de armas nucleares [em inglês, no first use] e aderiu a uma estratégia nuclear que é defensiva em natureza. A China não usará nem ameaçará usar armas nucleares contra Estados não-nucleares ou zonas livres de armas nucleares, e nunca entrará numa corrida armamentista com outro país. A China sempre manteve suas armas nucleares em níveis mínimos necessários para a garantia de sua segurança nacional (CHINESE MINISTRY OF NATIONAL DEFENSE 2016, apud KRISTENSEN; KORDA, 2019, p. 173, tradução nossa).

A despeito da continuidade da política nuclear declaratória da China, os debates sobre a postura nuclear chinesa contemporânea concentraram-se no questionamento sobre a possibilidade de transformações não declaradas oficialmente, especialmente na estratégia de "dissuasão mínima". Em tese, essa estratégia contemplaria apenas capacidades de ação contra-valor (ataque a alvos valorados pelo adversário, inclusive civis), mas não contra-força (que prevê o ataque específico às forças armadas e forças retaliatórias de um adversário potencial).

Johnston (1995-1996) defende que a postura nuclear chinesa teria iniciado um processo de transformação em meados dos anos de 1990, pois, segundo esse especialista, naquele momento, os estrategistas chineses temiam que a dissuasão mínima implicasse numa aquisição tão limitada de artefatos que tornaria o arsenal 
chinês muito vulnerável a um eventual primeiro ataque nuclear (p. 18). Nesse sentido, o autor relata que os especialistas chineses passaram a estabelecer uma distinção mais clara entre "dissuasão limitada" e "dissuasão mínima" a partir da década de 1990. Na dissuasão limitada, esperar-se-ia que as armas nucleares detenham o início de guerras tanto convencionais quanto nucleares. No entanto, caso falhe a dissuasão, armas nucleares seriam gradualmente usadas, visando ao controle de uma escalada no conflito (p. 12). Assim, a estratégia de "dissuasão limitada" contemplaria a possibilidade de que guerras nucleares possam ser travadas e vencidas. Em outras palavras, essa postura seria baseada no entendimento de que o uso (ou ameaça de uso) de armas nucleares contra-força e contra-valor pode levar um adversário a recuar, negando-Ihe a vitória em um conflito. Johnston acredita que a lista efetiva de alvos considerados apropriados pelos estrategistas chineses (alvos civis e alvos militares) dá apoio à hipótese de que a postura estratégica chinesa está se transformando em algo próximo da "dissuasão limitada", uma vez que, para esse autor, a dissuasão mínima envolveria apenas alvos contra-valor (p. 19).

Contudo, Johnston (1995-1996) pondera que, no momento em que escrevia sua análise, identificava-se uma grande lacuna entre os argumentos doutrinários que ele discutia e as capacidades nucleares efetivas da China (p. 31). Para o autor, essa lacuna devia-se ao fato de que a ideia de "dissuasão limitada" estabelecia diretrizes futuras para aquisição e implantação de tecnologia nuclear, mas que os resultados desses esforços levariam tempo para se tornarem visíveis.

No início dos anos 2000, Gill, Mulvenon e Stokes (2002) reconheciam a continuidade da política declaratória chinesa sobre armas nucleares, baseada nos seguintes princípios: 1) a permanência da política de não primeiro uso (em inglês, no first use), a qual implica que a natureza do arsenal nuclear chinês é eminentemente defensiva, sendo sua função apenas dissuadir um primeiro ataque por parte dos adversários da China); 2) a manutenção do compromisso de não usar armas nucleares contra Estados não nucleares e de trabalhar no âmbito do Conselho de Segurança para ajudar esses Estados no caso de que sofram um ataque nuclear; 3) a rejeição da ideia de dissuasão nuclear estendida ${ }^{9}$ e do desdobramento de armas nucleares para fora de suas fronteiras nacionais; e 4) o apoio às zonas livres de armas nucleares.

\footnotetext{
9 Tal estratégia implica em estender a ameaça de retaliação nuclear para os casos em que os territórios de aliados sejam atacados nuclearmente.
} 
Esses estudiosos identificavam certa coerência entre esses princípios e as possibilidades materiais de atuação do arsenal chinês. Nesse sentido, assim como Johnston, acreditavam que a postura nuclear chinesa poderia estar sujeita a alterações caso o arsenal chinês melhorasse em qualidade e quantidade. Consequentemente, Gill, Mulvenon e Stokes (2002) defendiam que a análise da postura nuclear chinesa deveria ser fundamentada naquilo que as capacidades contemporâneas ao estudo poderiam fazer, e não em intenções ou princípios declarados.

Nesse sentido, argumentavam que as forças estratégicas chinesas desafiavam a categorização simples como dissuasão "mínima" ou "limitada", uma vez que as forças da Segunda Artilharia chinesa (hoje renomeada como Força dos Mísseis) eram compostas por sistemas estratégicos e táticos de alcance, precisão e carga variados, que poderiam executar missões diversas. Segundo esses estudiosos, o arsenal de mísseis balísticos intercontinentais (ICBM), embora reduzido, constitui a base de uma força de dissuasão mínima (buscando viabilizar um eventual ataque retaliatório), enquanto os sistemas táticos funcionariam como sistemas ofensivos destinados a atacar as forças e as bases dos EUA na Ásia, compensando, portanto, a superioridade estadunidense em capacidades convencionais na eventualidade de um conflito convencional de grandes proporções.

Em contraste, Jeffrey (2007) contesta a opinião de que há evidências de uma revisão no padrão tradicional de desdobramento e emprego das forças nucleares chinesas ou na lógica estratégica subjacente. $\mathrm{O}$ autor argumenta que o objetivo do arsenal nuclear chinês continua ser 0 de desencorajar outras potências nucleares a usarem armas nucleares contra a China e o de retaliar qualquer Estado que o faça. Apoiando seu argumento, invoca características contínuas do arsenal nuclear chinês, o qual seria: "1) pequeno em número e baseado principalmente em mísseis balísticos terrestres, 2) mantido sob controle central e fora do estado de alerta, e 3) limitado em suas missões operacionais a ataques de retaliação" (p. 26, tradução nossa).

Em sentido similar, Yunzhu (2005), uma respeitada fonte chinesa sobre esse assunto, destaca as especificidades do pensamento chinês sobre dissuasão nuclear:

Se eu tiver que escolher entre as classificações ocidentais de dissuasão para descrever a postura de dissuasão nuclear chinesa, eu teria que usar o conceito de "dissuasão mínima" em comparação com a dissuasão máxima ou limitada. Pessoalmente, acho que a palavra "mínimo" tem uma conotação quantitativa muito forte que é enganosa. Às vezes, sugere um padrão quantitativo em vez de um padrão qualitativo. A palavra "mínimo" já há algum tempo é usada oficialmente em documentos do governo chinês. 
Mas o que quero enfatizar é que os estrategistas chineses consideram o conceito relativo, definido não apenas por números puros, mas por critérioschave como invulnerabilidade das forças nucleares, garantia de retaliação e credibilidade do contra-ataque. Quando um documento chinês diz que a China pretende possuir armas nucleares apenas no nível mínimo (ou mais baixo) para as necessidades de autodefesa, isso significa ter as capacidades mínimas, mas garantidas, para um segundo ataque retaliatório. Alguns estudos sugeriram uma mudança na postura nuclear chinesa em direção à dissuasão limitada, em que a China poderia empregar armas nucleares para deter guerras convencionais e nucleares e até mesmo para exercer o controle da escalada no caso de um confronto convencional. No entanto, a lógica básica do pensamento nuclear da China dita as armas nucleares como dissuasórias - não como um meio de vencer (YUNZHU, 2005, p. 4, tradução nossa).

Worztel (2007) aponta, entretanto, a existência de debates na China sobre a política de no-first use, isto é, questiona-se em que medida armas nucleares deveriam ser usadas diante de ataques convencionais de grande porte contra os sistemas estratégicos chineses. No caso de um alerta de ataque em curso, armas nucleares deveriam ser usadas preemptivamente? Exemplos dessa linha de pensamento são Rong Yu e Peng Guangqian:

Se as armas nucleares de uma das partes em guerra forem atacadas pelas armas convencionais do inimigo, resultando em radiação nuclear, contaminação nuclear ou mesmo explosão nuclear, isso poderá ser visto como um primeiro uso de armas nucleares? Na superfície, este é apenas um ataque convencional, mas, na verdade, seu impacto é pouco diferente de sofrer um ataque nuclear e sofrer perdas igualmente pesadas. Nesse caso, o ataque convencional também pode ser visto como rompendo o limiar nuclear, e os atacados terão dificuldade em evitar um contra-ataque nuclear, o que, por sua vez, aumentará bastante os riscos de que um dos lados inicie um ataque nuclear preventivo (apud YOSHIHARA; HOLMES, 2010, p. 147).

Argumentando a favor da visão de que a postura nuclear chinesa está mudando, Chase, Erickson e Yeaw (2009) ressaltam que os estrategistas chineses parecem estar promovendo reformas para aumentar a credibilidade da dissuasão chinesa. Segundo esses autores, o principal objetivo dessas reformas é melhorar a capacidade de sobrevivência e robustez, bem como a flexibilidade e a capacidade de resposta dos mísseis chineses. No que diz respeito à capacidade de sobrevivência, cientistas e engenheiros chineses têm discutido, em publicações de amplo acesso, uma série de contramedidas, como decoys (iscas), ogivas de manobra, sistemas múltiplos de ogivas e ataques preventivos (p. 81). Por fim, esses autores acreditam que a China esteja buscando o desenvolvimento de armas nucleares táticas para garantir a credibilidade de sua postura de dissuasão em todos os níveis da guerra (p. 87).

Fravel e Medeiros (2010), apesar de argumentarem pela continuidade da abordagem chinesa à estratégia nuclear desde a década de 1960, concordam que a 
China fez melhorias recentes na capacidade de sobrevivência de seus arsenais. Destacam que as mudanças na composição das forças nucleares da China enfatizaram o aumento da qualidade sobre a quantidade, a fim de alcançar uma capacidade segura de segundo ataque (p. 52). Em outras palavras, esses autores pensam que a China está buscando adquirir capacidades adequadas para alcançar a retaliação garantida.

Os autores explicam a continuidade da postura nuclear chinesa com base nas opiniões dos principais líderes da China desde Mao Tsé-tung, que veem as armas nucleares como ferramentas para deter a agressão e a coerção nuclear, que não devem ser usadas em combate. Além disso, os líderes chineses aderem à ideia de que um pequeno número de armas "sobrevivíveis" seria suficiente para lograr a dissuasão, ameaçando uma retaliação nuclear, o que Fravel e Medeiros (2007) chamam de doutrina de "retaliação garantida" (p. 57-58). Esses estudiosos acreditam que as políticas domésticas e organizacionais também são responsáveis pela evolução gradual da estratégia e das forças nucleares da China. Em particular, invocam a falta de recursos e de experiência em estratégia nuclear do Exército de Liberação Popular da China para explicar a subespecificação da estratégia e da doutrina nuclear da China antes dos anos 1990 (p. 66).

No entanto, os autores advogam que a busca por retaliação garantida não autoriza dizer que a estratégia nuclear da China seja de dissuasão mínima, uma vez que esse tipo de dissuasão implica que a China teria aderido a uma série de ideias que prescrevem o tamanho, a composição e as operações das forças nucleares. A China não está comprometida a perseguir apenas alvos indiscriminados (como mencionado anteriormente, fontes militares chinesas sugerem que as forças e as instalações militares do adversário podem ser alvos em um ataque de retaliação), nem a adquirir apenas um número específico de armas, que são atributos da dissuasão mínima (p. 79).

Da mesma forma, apesar de negar a ocorrência de mudanças fundamentais na postura nuclear chinesa, Jeffrey (2007) também reconhece que os chineses estão trabalhando para melhorar a capacidade de sobrevivência de seu arsenal nuclear sob condições de ataque nuclear, lembrando que, em agosto de 1995, a antiga Segunda Artilharia (hoje Força dos Mísseis) concluiu um projeto que supostamente criou uma rede de cavernas e túneis interconectados para armazenar seus mísseis (p. 33). 
A seu turno, Yoshihara e Holmes (2010) afirmam que os desenvolvimentos mais recentes nas forças nucleares da China não necessariamente quebram com uma estratégia minimalista, mas, sim, reforçam a dissuasão mínima (p. 133). Acredita-se que Pequim tenha mantido a avaliação de que uma pequena quantidade de armas nucleares é suficiente, desde que a capacidade de sobrevivência de seus arsenais seja garantida. No entanto, os desenvolvimentos dos arsenais adversários potenciais alteram os requisitos mínimos para garantir a capacidade de sobrevivência. Portanto, a ausência de mudança no pensamento estratégico da China não significa que o arsenal nuclear chinês permaneça intacto. Nas palavras desses estudiosos, "a mudança está ocorrendo dentro de um contexto mais amplo de continuidade" (p. 135). Ou, como afirma uma fonte chinesa:

À medida que várias capacidades de ataque de precisão crescem rapidamente e os sistemas de mísseis antibalísticos se desenvolvem internacionalmente, os padrões mínimos e as referências tecnológicas necessárias para a autodefesa devem ser incrementados em conformidade (SUN XIANGLI apud YOSHIHARA; HOLMES, 2010, p. 135).

Em suma, embora os estudiosos de política nuclear discordem quanto à ocorrência de grandes mudanças na postura nuclear chinesa (especialmente no que se refere à política de no first use e de dissuasão mínima), há consenso em reconhecer um novo e importante desdobramento: os atuais esforços de modernização nuclear têm se concentrado em melhorar a capacidade de sobrevivência das armas nucleares chinesas, potencialmente fornecendo à China capacidades críveis de realização de um segundo ataque retaliatório.

Em um recente "Boletim dos Cientistas Atômicos" sobre o status das forças nucleares chinesas, Kristensen e Korda (2019) estimam que este país tenha um total de 290 ogivas nucleares, uma quantidade que não variou muito desde o final da Guerra Fria. No entanto, os esforços de modernização não se concentraram na quantidade de ogivas, mas na qualidade dos sistemas de entrega. Nesse sentido, o general Jing Zhiyuan, que foi comandante da antiga Segunda Artilharia (hoje Força dos Mísseis), declarou que a "eficácia de elite" e a "eficácia suficiente" são a base do programa de modernização (apud YOSHIHARA; HOLMES, 2010, p. 136).

Kulacki (2011) enfatiza que os especialistas em armas nucleares da China confiam que suas ogivas nucleares são operacionais, detonando no caso de acionamento, mas temem pela capacidade de sobrevivência dos veículos de entrega e de suas instalações de comando e controle. Portanto, o problema da capacidade de sobrevivência parece estar impulsionando as melhorias atuais no arsenal da 
China e o foco nos sistemas de entrega. Em particular, os esforços de modernização da China estão focados na substituição de seus mísseis movidos a combustível líquido, lançados a partir de locais fixos, por mísseis a combustível sólido, que podem ser lançados de plataformas móveis. A mobilidade dos arsenais nucleares dificulta sua detecção por eventuais forças adversárias, reduzindo a probabilidade de que os mísseis da China possam ser destruídos em um primeiro ataque e desencorajando, assim, um primeiro ataque nuclear (p. 3-4).

Em particular, a maior mobilidade e a melhoria da capacidade de sobrevivência dos mísseis chineses podem ser obtidas por dois meios principais: a construção de mísseis terrestres móveis e a implantação de mísseis em submarinos. Os mísseis terrestres são priorizados no arsenal nuclear chinês: Kristensen e Korda (2019) estimam que Pequim tenha entre 180 e 190 mísseis balísticos nucleares terrestres capazes de carregar uma única ogiva cada (p. 171). Esses estudiosos estimam ainda que apenas 80 desses mísseis podem atingir o território continental dos EUA (p. 173). No entanto, é importante notar que este é um aumento significativo em relação aos números da Guerra Fria mostrados anteriormente. Em 1984, a China tinha apenas dois mísseis que poderiam atingir os EUA continentais.

Da mesma forma, em seu relatório anual ao Congresso, o Departamento de Defesa dos EUA afirma que a China está modernizando suas forças nucleares, adicionando sistemas de entrega com maior mobilidade. O Departamento de Defesa também acredita que a China está desenvolvendo um novo ICBM móvel (míssil balístico intercontinental) capaz de transportar um veículo de reentrada múltiplo (MIRV).

Kristensen e Norris $(2006,2011)$ destacam que a China está substituindo o DF-5 original por uma versão modificada e de maior alcance, o DF-5A, que atinge $13.000 \mathrm{~km}^{10}$. Outro desenvolvimento recente importante é a implantação de dois mísseis móveis movidos a combustível sólido: o DF-31 e o DF-31A. O último é uma

\footnotetext{
10 Um relatório entregue à Câmara dos Deputados no final dos anos 1990, conhecido como "Relatório Cox", alegou que o DF-5 era uma emulação clara da tecnologia dos EUA, que teria sido roubada pela China na década de 1950. No entanto, não se pode dizer com certeza que a emulação realmente aconteceu, pois essa alegação foi desacreditada por avaliações subsequentes do Relatório Cox. Em especial, o Centro de Segurança e Cooperação Internacional da Universidade de Stanford (CISAC) publicou uma revisão do Relatório Cox por um grupo de estudiosos da Universidade de Harvard, Universidade de Stanford e do Laboratório Nacional Lawrence Livermore, que sustentavam que o relatório não fornecia informações suficientes para atribuir as armas nucleares da China a fontes americanas. O relatório afirma, por exemplo, que a próxima geração de armas termonucleares chinesas será baseada em tecnologia roubada dos EUA, mas não apresenta nenhuma evidência para apoiar essa alegação. Além disso, estudiosos argumentam que o roubo de informações não poderia levar a uma nova geração sem a condução de testes nucleares. Em suma, o relatório é acusado de não ter rigor acadêmico e exibir erros factuais e inferências injustificadas (KRISTENSEN; NORRIS, 2006, p. 23-28; e p. 73).
} 
extensão do primeiro e alcança 11.200 quilômetros, podendo atingir o território continental dos EUA. Destaca-se também o desdobramento, a partir de 2016, de cerca de 80 mísseis DF-26, de alcance intermediário, os quais não podem atingir o território continental dos EUA, mas estariam aptos a atacar bases estadunidenses como Guam. Ademais, o DF-26 pode ser armado convencionalmente, podendo ser usado contra porta-aviões dos EUA (KRISTENSEN; KORDA, 2019, p. 174).

Por outro lado, tendo em vista que os mísseis não-móveis permanecem importantes para a China, outra ação esperada desse Estado em seu esforço para melhorar a capacidade de sobrevivência de seu arsenal é o fortalecimento dos locais de armazenamento. De fato, de acordo com Zhang (2012), a mídia chinesa, incluindo o Diário de Defesa Nacional, do Exército de Libertação Popular, informou que a unidade de engenharia da antiga Segunda Artilharia começou a construir uma "grande muralha subterrânea" (ou uma série de túneis para armazenar armas nucleares) em 1985 e terminou sua primeira fase cerca de 10 anos depois.

Finalmente, destacam-se os desdobramentos relacionados aos submarinos nucleares chineses. $\mathrm{Na}$ atualidade, a China possui 4 submarinos nucleares da classe Jin, sendo que cada qual possui capacidade para o armazenamento de 12 mísseis balísticos JL-2 (cujo alcance estimado é de 7.200km). Nesse sentido, Kristensen e Korda (2019) estimam que o JL-2, se lançado de águas próximas à China, possa atingir o Alasca, Guam, Havaí, Rússia e Índia, mas não os EUA continental. A despeito do fato de que esses investimentos em tese aumentem a sobrevivência e a mobilidade do arsenal nuclear chinês, não se sabe ao certo se esses submarinos já foram enviados em patrulhas dissuasórias (com armas nucleares a bordo).

Em suma, ao longo dos últimos anos, embora haja uma ênfase maior em mísseis terrestres (que são da responsabilidade da Força dos Mísseis), a China tem procurado diversificar seus meios de entrega, de modo a garantir a posse da chamada "tríade nuclear", que implica na posse de mísseis terrestres, mísseis lançados de submarinos e bombardeiros. Dentre as 290 ogivas chinesas, cerca de 220 seriam aptas para o lançamento por mísseis balísticos terrestres (contabilizados entre 180 e 190) e o restante por mísseis balísticos lançados do mar e por bombardeiros (KRISTENSEN; KORDA, 2019).

Essa diversificação, somada aos demais investimentos na sobrevivência das forças nucleares chinesas, denota uma maior preocupação com a garantia de forças de segundo ataque, as quais reforçam o poder dissuasório do arsenal nuclear 
chinês, ao mesmo tempo em que tornam a China menos vulnerável a ameaças de uso da força contra o seu território, contribuindo significativamente para o melhor posicionamento deste país no sistema internacional contemporâneo.

Nesse sentido, argumenta-se aqui que os investimentos chineses em armas nucleares no pós-Guerra Fria estão inseridos em um processo de balanceamento interno da China em relação aos EUA. A década de 1990 testemunhou um aumento geral nos gastos chineses com defesa e a ampla modernização das forças militares chinesas, permitindo melhorias críticas no arsenal nuclear deste país. Em especial, o investimento na capacidade de sobrevivência das armas nucleares chinesas ocorre em reação ao arsenal nuclear dos EUA, dada a primazia nuclear desse país no período imediatamente posterior ao fim da Guerra Fria.

De acordo com Lieber e Press (2007), a primazia nuclear significou que os EUA poderiam, em um primeiro ataque, destruir completamente as forças retaliatórias nucleares de Rússia ou China, impedindo, assim, uma eventual retaliação nuclear ao território estadunidense e neutralizando as armas nucleares russas ou chinesas. Para apoiar esta afirmação, os autores recordam os principais desenvolvimentos no arsenal estadunidense nos últimos anos, como o lançamento dos mísseis Trident II D-5 para toda a frota de SSBN, a colocação de ogivas W88 de alto rendimento em muitos desses mísseis e o lançamento dos bombardeiros B-2. Os autores argumentam que essas armas foram fundamentais para fornecer aos EUA uma vantagem de primeiro ataque, uma vez que possuem uma combinação sem precedentes de capacidade de lançamento com prazo de aviso mínimo, alta precisão e grande rendimento (p. 83).

Diante desse quadro, o comportamento chinês em relação às armas nucleares no pós-Guerra Fria é condizente com o balanceamento interno via offsetting: a China reagiu à primazia nuclear dos EUA, buscando garantir a sobrevivência de seu arsenal a um eventual primeiro ataque, gerando incerteza nas autoridades estadunidenses de que um primeiro ataque desarmaria completamente a China. Uma forte evidência do fato de que os chineses estão tentando compensar as capacidades dos EUA de primeiro ataque é o duplo caminho dos esforços nucleares da China: a melhoria da capacidade de sobrevivência de mísseis terrestres e a construção concomitante (lenta, mas contínua) de uma capacidade dissuasória submarina. Isso porque os EUA são o único país que poderia ameaçar a China com um primeiro ataque que a desarmaria em terra e no mar simultaneamente (YOSHIHARA; HOLMES, 2010, p. 140). 


\section{Considerações finais}

Em diálogo com a teoria da balança de poder, este artigo defendeu que o processo de balanceamento interno pode ser considerado um importante fator de transformação estrutural, potencialmente ensejando o fim do sistema internacional unipolar inaugurado com o fim da Guerra Fria. Argumentou-se que um dos setores em que se manifesta o balanceamento interno é o nuclear, na medida em que pólos em ascensão devem se proteger contra eventuais usos ou ameaças de uso de armas nucleares por parte do pólo mais forte do atual sistema internacional.

Buscamos demonstrar que a China empreendeu comportamentos condizentes com o balanceamento interno, tanto durante a Guerra Fria quanto na contemporaneidade. No entanto, durante a Guerra Fria, os resultados dos investimentos chineses no setor nuclear eram insuficientes para proteger o território desse país de um primeiro ataque que poderia destruir completamente sua capacidade retaliatória. Em oposição, na atualidade, a China empreende esforços no sentido de salvaguardar seu arsenal de um possível primeiro ataque estadunidense, adquirindo capacidades retaliatórias críveis para a realização de um segundo ataque. Nesse sentido, os atuais esforços nucleares da China parecem estar mais próximos de atender aos requisitos estabelecidos neste artigo para caracterizar o comportamento de um Estado como balanceamento interno. Isso porque, embora o resultado final dessas ações esteja muito longe do equilíbrio com as capacidades estadunidenses, os empreendimentos recentes da China diminuem a distância nuclear entre a China e os EUA. Pela primeira vez em sua história, a China parece ter a capacidade de impor sérios danos ao território continental dos EUA em retaliação a um primeiro ataque nuclear estadunidense. Essa nova situação não elimina a superioridade nuclear dos EUA, mas torna a decisão de empregar armas nucleares contra a China muito mais difícil: uma decisão dos EUA de iniciar uma guerra nuclear deve levar em consideração a maior probabilidade de perda de vidas estadunidenses.

No entanto, na hipótese (improvável, mas possível) de que os EUA iniciem uma guerra nuclear contra a China, é incerta a capacidade desse último de prosseguir para além de um segundo ataque retaliatório. Diante disso, conclui-se que, na arena nuclear, o processo de balanceamento interno da China em relação aos EUA está em curso, mas que seu progresso tem ocorrido de modo mais lento e menos intenso do que seria esperado pela teoria da balança de poder. 


\section{REFERÊNCIAS}

CHASE, Michael S.; ERICKSON, Andrew S.; YEAW, Christopher. Chinese Theater and strategic missile force modernization and its implications for the United States, Journal of Strategic Studies, v. 32, n. 1, p. 67-114, 2009.

BIN, Li. Paper tiger with whitened teeth. China Security, p. 78-89, Autumn 2006.

DAWOOD, Layla Ibrahim Abdallah. China versus the United States: is bipolarity back? A study of Internal Balancing as a possible source of international systemic change. Tese (Doutorado em Relações Internacionais)-Pontifícia Universidade Católica do Rio de Janeiro, Rio de Janeiro, 2013.

DEPARTMENT OF DEFENSE OF THE UNITED STATES OF AMERICA; Annual report to Congress: military and security developments involving the People's Republic of China, 2010.

FRAVEL, M. Taylor; MEDEIROS, Evan S. China's search for assured retaliation. The evolution of Chinese nuclear strategy and force structure. International Security, v. 35, n. 2, p. 48-87, Fall 2010.

GILL, Bates; MULVENON, James; STOKES, Mark. The Chinese Second Artillery Corps: transition to credible deterrence. In: MULVENON, James; YANG, Andrew (Ed.). The People's Liberation Army as organization. RAND, p. 510-586, 2002.

GILL, Bates; NI, Adam. The People's Liberation Army Rocket Force: reshaping China's approach to strategic deterrence, Australian Journal of International Affairs, 2019. Disponível em: https://doi.org/10.1080/10357718.2018.1545831. Acesso em: 26 set. 2020.

GOLDSTEIN, Avery. Deterrence and security in the 21st century. China, Britain, France and the enduring legacy of nuclear revolution. Stanford: Stanford University Press, 2000.

JEFFREY, G. The minimal means of reprisal. China's search for security in the nuclear age. Cambridge: The MIT Press, 2007.

JOHNSTON, Alastair lain. China's New "Old Thinking": The Concept of Limited Deterrence. International Security, v. 20, n. 3, p. 5-42, Winter 1995-1996.

KRISTENSEN, Hans; KORDA, Matt. Chinese nuclear forces, 2019. Bulletin of the Atomic Scientists 2019, v. 75, n. 4, p. 171-178, 2019. Disponível em:

https://www.tandfonline.com/doi/pdf/10.1080/00963402.2019.1628511?needAccess=true. Acesso em: 21 maio 2020.

KRISTENSEN, Hans M.; NORRIS, Robert S.; MCKINZIE, Matthew G. Chinese nuclear forces and U.S. nuclear war planning. The Federation of American Scientists \& The Natural Resources Defense Council. Nov. 2006.

KRISTENSEN, Hans M.; NORRIS, Robert S. Global nuclear weapons inventories, 19452010. Bulletin of the Atomic Scientists, v. 66, n. 4, p. 77-83, 2010.

KRISTENSEN, Hans M.; NORRIS, Robert S. Chinese nuclear forces, 2011. Bulletin of the Atomic Scientists, v. 67, n. 6, p. 81-87, 2011.

KULACKI, Gregory. China's Nuclear Arsenal: status and evolution. Union of concerned scientists. Oct. 2011.

LAYNE, C. The unipolar illusion: why new powers will rise. International Security, v. 17, n. 
4, p. 5-51, 1993.

LEWIS, Wilson John; HUA, Di. China ballistic missile programs. Technologies, strategies, goals. International Security, v. 17, n. 2, Fall 1992.

LEWIS, Wilson John; LITAI, Xue. China builds the bomb. Stanford: Stanford University Press, 1988.

LEWIS, Wilson John; LITAI, Xue. China's strategic seapower. The politics of force modernization in the nuclear world. Stanford: Stanford University Press, 1994.

LIEBER, Keir; PRESS, Daryl. The end of mad? The nuclear dimension of U.S. primacy. International Security, v. 30, n. 4, p. 7-44, Spring 2006.

LIEBER, Keir; PRESS, Daryl. U.S. nuclear primacy and the future of the Chinese deterrent. China Security, p. 66-89, Winter 2007.

WALTZ, K. N. Theory of international politics. New York: McGraw-Hill, 1979.

WOHLFORTH, W. C. The stability of a unipolar world. International Security, v. 24, n. 1, p. 5-41, 1999.

WOHLFORTH, W. C. et al. Testing balance of power theory in world history. European Journal of International Relations, v. 13, n. 2, p. 155-185, 2007.

WORTZEL, Larry M. China's nuclear forces: operations, training, doctrine, command, control, and campaign planning. May 2007. Available at:

www.StrategicStudiesInstitute.army.mil. Access on: 10th Oct. 2011.

YOSHIHARA, Toshi; HOLMES, James. Red star over the Pacific. China's rise and the challenge to U.S. marine strategy. Annapolis: Naval Institute Press, 2010.

YUNZHU, Yao. Chinese Nuclear Policy and the future of minimum deterrence. Strategic Insights, v. 4, n. 9, Sept. 2005.

ZHANG, Hui. The defensive nature of China's "underground great wall". Bulletin of the Atomic Scientists. 16 Jan. 2012.

\section{NOTAS DE AUTOR}

\section{CONTRIBUIÇÃO DE AUTORIA}

Layla Ibrahim Abdallah Dawood - Concepção. Coleta de dados, Análise de dados, Elaboração do manuscrito, revisão e aprovação da versão final do trabalho.

\section{FINANCIAMENTO}

Não se aplica.

CONSENTIMENTO DE USO DE IMAGEM

Não se aplica.

APROVAÇÃO DE COMITÊ DE ÉTICA EM PESQUISA

Não se aplica. 


\section{LICENÇA DE USO}

Este artigo está licenciado sob a Licença Creative Commons CC-BY. Com essa licença você pode compartilhar, adaptar, criar para qualquer fim, desde que atribua a autoria da obra.

\section{HISTÓRICO}

Recebido em: 06-09-2020

Aprovado em: 29-10-2020 